Tates, K., Meeuwesen, L., Bensing, J., Elbers, E.

Joking or decision-making?: affective and instrumental behaviour in doctor-parent-child communication.

Psychology and Health: 17, 2002, nr. 3, p. p. 281-295

\begin{tabular}{|l|l|}
\hline Postprint Version & 1.0 \\
\hline Journal website & http://dx.doi.org \\
\hline Pubmed link & \\
\hline DOI & $10.1080 / 08870440290029548$
\end{tabular}

*Corresponding author. Tel.: +31 30272 9700. Fax: +31 30272 9729. E-mail: k.tates@nivel.nl

\title{
JOKING OR DECISION-MAKING? AFFECTIVE AND INSTRUMENTAL BEHAVIOUR IN DOCTOR- PARENT-CHILD COMMUNICATION
}

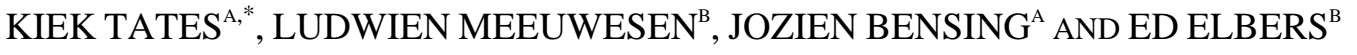 \\ a Netherlands Institute for Health Services Research (NIVEL), P.O. Box 1568, 3500 BN Utrecht, The \\ Netherlands; \\ b Department of General Social Sciences, Utrecht University
}

\begin{abstract}
Advocating active child participation in medical encounters is in line with demands for shared decisionmaking and informed consent. The sparse literature on doctor-child communication, however, conceptualizes children as passive participants and depicts the stereotype of a 'joking' relationship, which is limited mainly to affective behaviour. This descriptive study explores the nature of communication in the doctor-parent-child triad at the general practitioner's surgery. Video-taped observations of 106 medical interviews were analysed in terms of affective and instrumental behaviour. An adjusted version of the Roter Interaction Analysis System (RIAS) was used to analyse the doctor-parentchild triad. The videos, taken over a period of almost twenty years, made it possible to look for the presence of effects over time. The results show that the stereotype of doctorchild interaction as a joking relationship does not hold true. In fact, besides affective behaviour, there was more exchange of instrumental behaviour. The age of the child was positively related to child participation. Time appears to have had a rather limited effect on the child's participation. Whereas GPs accommodated their behaviour to the child's age by displaying more instrumental behaviour towards older children, the nature of parental behaviour appeared to be almost constant. The results are discussed in terms of the relevance for shared decision-making in medical consultations regarding children, and recommendations are given for medical practice and health education.
\end{abstract}

\section{INTRODUCTION}

The development of a patient-centred approach and processes of shared decision-making are central themes in research on medical communication (Stewart et al., 1995; Blaauwbroek, 1997; Van den Borne, 1998; Verhaak et al., 1998). It is increasingly acknowledged that children should also be involved in decisions about their own health care (Alderson and Montgomery, 1996; Rylance, 1996; Hart and Chesson, 1998). Until recently however, children have been mainly conceptualized as passive participants, and their role in medical communication has largely been ignored in research (Tates and Meeuwesen, 2001). This contrasts with studies emphasizing the capability of children to play an active and negotiative role in interaction with adults (Elbers et al., 1992) and their understanding of medical issues (Colland, 1990; Alderson and Montgomery, 1996). More direct 
Tates, K., Meeuwesen, L., Bensing, J., Elbers, E.

Joking or decision-making?: affective and instrumental behaviour in doctor-parent-child communication.

Psychology and Health: 17, 2002, nr. 3, p. p. 281-295

communication between physician and child, including discussion about the treatment plan, contributes to greater patient satisfaction and better health outcomes (Colland, 1990; Holtzheimer et al., 1998). From the perspective of patient-centred care, the interaction between physician and child deserves special attention. While it has been common to restrict the analysis mainly to the doctorparent dyad, the present study explicitly takes the doctor-parent-child triad as the unit of analysis, and attempts to describe the nature of the communication between doctor, parent, and child at the general practitioner's surgery in the Netherlands.

When seeing a general practitioner (GP), patients have two basic needs: there is the cognitive need to be informed (the need to know and understand), and the emotional need to be taken seriously (the need to feel known and understood) (Engel, 1988). In concordance with this, the GP is assumed to possess two types of skills: instrumental, or task-related behaviour, and affective, or socio-emotional behaviour. Instrumental behaviour involves problem-solving skills such as asking questions and providing information, while affective communication refers to those aspects needed to establish a therapeutically effective relationship, such as reflecting feelings and showing empathy and concern (Roter, 1989). Depending on the specific needs of the patient and the goal of the interview, a balance between instrumental and affective behaviour characterizes effective communication between doctor and patient (Bensing, 1991; Bensing et al., 1996).

The few studies that have been conducted largely depict the stereotype of doctor- child communication as being restricted to affective behaviour, especially joking and social talk (Freemon et al., 1971; Pantell et al., 1982; Aronsson and Rundstro“" m, 1989; Van Dulmen, 1998). Although physicians tend to rely on the child for obtaining information, diagnostic and treatment information are primarily directed to the parent (Pantell et al., 1982; Worobey et al., 1987; Van Dulmen, 1998). In general, the conversational contribution of the child is very limited, between 2 and $14 \%$ (Tates and Meeuwesen, 2001). The child's conversational contribution appears to be strongly related to his/her age (Meeuwesen et al., 1998; Van Dulmen, 1998). Older children take more initiatives themselves, and interrupt adult interactions more frequently. In addition, GPs appear to take the child's age into account by addressing an older child more directly and by allocating fewer turns to the parent as the child's age increases (Tates and Meeuwesen, 2000).

Over the past three decades, a number of important changes have taken place in doctor-patient communication in general. The development of the patient-centred approach and demands regarding shared decision-making and informed consent evoked a shift in the participants' roles in medical consultation (Stewart et al., 1995; Blaauwbroek, 1997; Van den Borne, 1998). As a result, the doctorpatient relationship has developed from being highly asymmetrical towards being more egalitarian, and patients have become more emancipated and autonomous over the years (Ong et al., 1995; Roter, 2000). A parallel can be seen in the interaction between parent and child, in that parenting has become less controlling and authoritarian, and adultchild interactions are increasingly characterized by a greater openness towards the child (De Swaan, 1988; DuBois-Reymond, 1993). Results of a previous study show that the child's control in the medical consultation is rather limited, although, over the years, the participation of the child has become more active (Tates and Meeuwesen, 2000).

This study addresses the following research questions:

1. How can the nature of doctor-parent-child communication be characterized in terms of affective and instrumental behaviour, and in terms of child-centredness and parent-centredness?

2. Does the child's age affect the communication patterns within the doctor-parent- child triad?

3. Have any changes in doctor-parent-child communication taken place over the past few decades?

Regarding the first question, it may be expected that doctor-child interaction is more affective in nature, and is primarily directed at establishing a good relationship. Communication with parents is likely to be more task-related and is assumed to involve more instrumental behaviour, such as information exchange and decision-making.

As the child's age increases, an increase in instrumental behaviour is expected between the participants.

Regarding the third question, it is expected that in the course of time GPs might have become more child-centred, by taking more account of the child's view. One might assume that there has been an increase in instrumental behaviour between GP and child, e.g. by the GP including the child more in the diagnostic process and the decision- making about choice of treatment. 


\section{METHOD}

\section{Sample}

This study is based on 106 video recordings of medical interviews at the GP's surgery. In the Dutch health care system the GP, who is comparable to a family physician, has a gate-keeping role: patients may only consult a specialist after referral by a GP, and $90 \%$ of all complaints are treated by GPs (Van Suijlekom-Smit and Crone-Kraaijeveld, 1994; De Melker, 1997). Thus the GP is the first responsible health care provider, including primary care and preventive care. About one in six consultations involves a child under the age of 16 . The videos were drawn from a large collection $(n=2500)$ of medical interviews with patients of all ages, which have been collected since 1975, and held by the Netherlands Institute for Health Services Research (NIVEL). A selection was made based on rigorous demands of technical quality. This was necessary since many of the earlier videos were of poor quality. The application of these and other relevant criteria (a triad of doctor-parent-child, and the age of the child: 4-12 years), supplemented by matching for age, gender and type of complaint of the child patient, resulted in a dataset of 36 videos for the period 1975-1978, 36 videos for 1988-1989, and 34 videos for 1993.

The unequal distribution of time between the three periods is a consequence of the availability of data at the start of the project. Data from these three periods allowed a comparison to be made crosssectionally, but not longitudinally, while the participants differed over the three periods (Hertzog, 1995). In the majority of the consultations selected $(n=88)$, the child was accompanied by the mother. All children had previously seen the GP. Fifty-eight different GPs participated in the study: 22 in period 1 (mean 1.6 consultations), 15 in period 2 (mean 2.4 consultations), and 21 in period 3 (mean 1.6 consultations). Because the majority was male $(n=53)$, it was not possible to assess the effect of physician's gender on the communication patterns in the triad. The mean duration of the consultation was almost $7 \mathrm{~min}$. Table I shows the composition of the sample.

\section{[ TABLE 1 ]}

\section{Measures}

The verbal and nonverbal communication between doctor, parent and child was measured directly from the video recordings. Before coding, the medical interview was divided into segments, viz. 1: the medical history, 2: the physical examination, and 3: the conclusion segment (diagnosis and treatment information). This sequential pattern is characteristic of medical interviews (Byrne and Long, 1976; Roter and Hall, 1992).

\section{Affective and Instrumental Behaviour}

The verbal communication was analysed using an adjusted version of the Roter Interaction Analysis System (RIAS), a well-documented, widely used system in the USA and the Netherlands for coding both doctor and patient communication (Roter, 1989; Bensing and Dronkers, 1992). This system distinguishes instrumental (task-focused) and affective (socio-emotional) verbal behaviour in doctors and patients, reflecting the two main purposes of the medical consultation: information exchange and the creation of a good interpersonal relationship. The unit of analysis is the verbal utterance, defined as the smallest discernable segment of speech to which a coder can assign a classification. An utterance may vary in length from a single word or clause to a complete sentence. All utterances are categorized in a mutually exclusive way. All behaviour is merged into 16 categories, almost identical for doctor, parent and child (Van Dulmen, 1998). The affective dimension includes social behaviour, agreement, paraphrase, verbal attention, showing concern, reassurance and disagreement (for parent, child and doctor). The instrumental dimension contains asking for clarification, asking questions (medical/ therapeutic), asking questions (psychosocial), giving information (medical/therapeutic), giving information (psychosocial), counselling (doctor), other.

As the RIAS was designed and applied to measure the communication of dyads, the application of the RIAS in triadic communication was hitherto restricted to the analysis of two dyads, e.g. doctorparent and doctor-child (Van Dulmen, 1998; Wissow et al., 1998). Since the aim of the present study was to focus explicitly on the triadic communication between doctor, parent and child, a number of adjustments were made, the most important being the notation of the initiative and the allocation of 
Tates, K., Meeuwesen, L., Bensing, J., Elbers, E.

Joking or decision-making?: affective and instrumental behaviour in doctor-parent-child communication.

Psychology and Health: 17, 2002, nr. 3, p. p. 281-295

each utterance and for each participant. Additionally, a category 'both' was included, for those cases where the speaker addresses both the other participants simultaneously, or in cases where it is not clear to whom the speaker is talking.

All 106 consultations were coded by two trained observers. The interrater reliability (Pearson's correlation coefficient) of physician categories was between 0.73 and 0.96 (mean 0.89 ), and of parent categories between 0.66 and 0.98 (mean 0.84). No interrater reliability (IRR) could be calculated for child categories, because none of these occurred in more than two percent of cases, which is the criterion for calculating the IRR. Factor Analysis of the RIAS categories revealed six clusters, two of which were affective in nature and four instrumental.

Affective behaviour:

1. Social behaviour and partnership building (based on social behaviour, agreements, showing concern, reassurance and paraphrasing)

2. Involvement (verbal attention, disagreement)

Instrumental behaviour:

3. Counselling and advice (medical counselling, psychosocial counselling, others)

4. Medical information exchange (medical questions, information on medical condition and treatment)

5. Psychosocial information exchange (psychosocial questions, information on psychosocial condition and treatment)

6. Consultation structuring and clarification (directions and instructions, requests for repetition of previous statements).

\section{Global Affect Ratings}

In addition to the above-mentioned verbal categories, the affective context of the videotaped interviews, beyond the significance of the words spoken, was rated by means of three affect scales (Roter, 1989; Bensing, 1991). The general affective climate of the medical interview seems to be positively related to good communication and patient satisfaction. The affect scales are warmth, nervousness, and irritation. They were rated on six-point scales (1=low, $6=$ high) for each participant separately. The interrater reliability of a total of 18 scales (see Table III) was high (ranging from 0.83 to 0.99$)$.

\section{[ TABLE 3 ]}

\section{Patient-Centredness}

GP's child-centredness and parent-centredness were measured separately using fivepoint Likert scales (1=not at all, $5=$ very) in order to obtain a global indication of the extent to which the GP took the child's or the parent's view into consideration during (1) the medical history-taking, (2) the conclusion segment, and (3) the extent to which the GP responded adequately to the contributions of child and parent, respectively (Bensing et al., 1996; Van der Pasch and Verhaak, 1998). The interrater reliability (Pearson correlation coefficient) was good (GP's child-centredness 0.79; GP's parentcentredness $0.83)$.

\section{Statistics}

Descriptive statistics were used to report the affective and instrumental behaviour. The RIAS categories were each analysed separately for GP, parent and child as percentages of all utterances and the ratios of affective/instrumental utterances were calculated. This descriptive analysis indicated that the distribution of the data was non-normal. The Kolmogorov-Smirnov Goodness of Fit Test revealed that the variables were equally positively skewed. In addition, non-parametric Kruskal-Wallis analyses yielded the same results as multivariate analyses. While considering the data as near-normally distributed, one-way analyses were performed, breaking down results by period and age. Additionally, multiple range tests (Bonferroni) were performed to compare the groups. 
Tates, K., Meeuwesen, L., Bensing, J., Elbers, E.

Joking or decision-making?: affective and instrumental behaviour in doctor-parent-child communication.

Psychology and Health: 17, 2002, nr. 3, p. p. 281-295

\section{RESULTS}

\section{Affective and Instrumental Behaviour}

Table II presents an overview of the participants' contribution in terms of affective and instrumental behaviour as well as allocation. The GPs' contribution to the consultation was $52 \%$, whereas parental and children's contribution were 38.4 and $9.6 \%$, respectively. In general, the ratio of affective versus instrumental behaviour was 41 and 59\%. Most of the GPs' behaviour was instrumental, both in interaction with the parent $(21.2 / 33.9 \times 100=63 \%)$ and the child patient $(8.4 / 14.4 \times 100=58 \%)$. Of the parental behaviour, $56 \%$ was instrumental, irrespective of the addressee. The child displayed relatively more instrumental behaviour towards the GP (60\%) than towards the parent (51\%). About two thirds (65\%) of the affective and instrumental verbal interaction occurred between GP and parent, 21\% between GP and child, 7\% between parent and child. The other behaviour was not directed explicitly to one of the others ( $7 \%$ both directed).

\section{[ TABLE 2 ]}

The affective cluster 'social behaviour and partnership building', (social conversation, agreements, concern, reassurance and paraphrasing) occurred the most frequently (39.2\%), followed by the instrumental cluster 'medical information exchange' (29.8\%). 'Counselling/advice' and 'consultation structuring and clarification' were represented modestly (13.8 and 12.4\%), while 'psychosocial information exchange' and 'involvement' rarely occurred (3.1 and $1.7 \%$ ).

A closer look at the separate clusters revealed that the GP directed 'social behaviour and partnership building' twice as much to the parent as to the child. Most of the GP's child-directed social behaviour and partnership building took place during the physical examination segment of the interview (1st segment $6 \%$, 2nd segment 7\%, 3rd segment $5 \% ; F=4.19, p<0.05$ ); whereas GPs' social behaviour and partnership building towards the parent were relatively more frequent in the other two segments (1st segment $14 \%$, 2nd segment $9 \%$, 3rd segment $13 \% ; F=15.68, p<0.001)$. The parent directed most of the social behaviour and partnership building to the GP in the conclusion segment (1st segment 10\%, 2nd segment $9 \%$, 3rd segment $18 \% ; F=45.24, p<0.001$ ).

The greater part of instrumental behaviour involved medical information exchange (29.8\%), and counselling and advice (13.8\%), and mostly took place between the two adult participants. The GP addressed $76 \%$ of the medical information to the parent, and mainly during the last two segments (1st segment $7 \%$, 2nd segment $10 \%$, 3rd segment $12 \% ; F=7.45, p<0.001$ ). In addition, $81 \%$ of GPs' statements concerning counselling and advice were parent-directed and mainly given in the conclusion segment (1st segment $3 \%$, 2nd segment $3 \%$, 3rd segment $10 \% ; F=51.36, p<0.001$ ). In contrast with the medical information exchange between GP and parent, most exchange of medical information between GP and child took place at the beginning of the consultation, during the medical historytaking and physical examination (1st segment 3\%, 2nd segment $4 \%$, 3rd segment $1 \%$; $F=8.48$, $p<0.001)$. In parallel with this, the child also directed medical information to the GP mostly during these two segments (1st segment $4 \%$, 2nd segment $3 \%$, 3rd segment $1 \% ; F=13.63, p<0.001$ ). With regard to the structure of the consultation, half the amount of GPs' structuring utterances were directed at the child, mainly during the physical examination (1st segment $2 \%$, 2nd segment $18 \%$, 3rd segment $2 \% ; F=91.93, p<0.001$ ). More than $60 \%$ of the parental utterances regarding consultation structuring and clarification were directed to the child.

\section{Global Affect Ratings}

A focus on the affect ratings (Table III) revealed that the GPs showed a fair amount of warmth towards the parent and the child. The parents and children also showed warmth, but less than the doctor.

The participants displayed little nervousness and irritation towards each other.

\section{Patient-Centredness}

Table IV shows the means of the global ratings of the GPs' child-centredness and parent-centredness in the medical history segment, in the conclusion segment, and as an overall rating on adequate response. 
Tates, K., Meeuwesen, L., Bensing, J., Elbers, E.

Joking or decision-making?: affective and instrumental behaviour in doctor-parent-child communication.

Psychology and Health: 17, 2002, nr. 3, p. p. 281-295

\section{[ TABLE 4 ]}

On all three measures, the GPs' child-centredness was rather low, although in the medical historytaking segment it was higher than in the conclusion segment. The GPs' parent-centredness was on all scores significantly higher than the child-centredness ( $p<0.001)$, especially in the conclusion segment.

\section{The Effect of Age}

The child's age and the period during which the consultations were recorded showed significant effects on the nature of the medical communication. This did not hold true for participants' gender or type of complaint. An overview will be given of the most salient effects.

Regarding the age of the child, it turned out that the older the child, the more the GP directed instrumental behaviour to the child itself (4-6 years $6 \%$, 7-9 years $8.5 \%, 10-12$ years $10.5 \% ; F=4.43$, $p<0.01$ ), or to child and parent together (both), and less to the parent (4-6 years 25\%, 7-9 years 20\%, $10-12$ years $18.5 \% ; F=5.19, p<0.01)$. In return, older children themselves displayed more instrumental behaviour towards the GP (4-6 years $2 \%, 7-9$ years: $3 \%, 10-12$ years $6 \% ; F=13.50, p<0.001$ ). The nature of the parental behaviour did not appear at all to be affected by the child's age.

Table V contains data of the clusters showing significant differences as an effect of the child's age. These effects were constrained to the instrumental categories, and to doctor and child, but not the parent. The exchange of medical information between GP and child intensified as the child's age increased. The older the child, the more GPs' exchange of medical information was directed to the child alone, or to child and parent together. Conversely, older children intensified the exchange of medical information with both the GP and the parent. In addition, the GP directed less counselling and advice to the parent as the child's age increased, and more to child and parent together. The amount of GPs' psycho-social information exchange appeared to be negatively associated with the child's age. Although the exchange of psycho-social information is rare, as we have seen, it seems to be seldom discussed when children become older.

\section{[ TABLE 5 ]}

The amount of parental physician-directed warmth was associated with the child's age: parents displayed less warmth towards the GP as their child's age increased (4-6 years $X=3.8$, 7-9 years $X=3.4,10-12$ years $X=3.4 ; F=2.99, p<0.05$ ). Younger children expressed more nervousness than older children in interaction with the GP (4-6 years $X=1.6,7-9$ years $X=1.2,10-12$ years $X=1.1 ; F=4.63$, $p<0.01)$. The amount of irritation displayed in the doctor-parent-child triad was very low and was not age-dependent.

The degree of GPs' child-centredness during the medical history-taking appeared to be positively associated with the child's age: the older the child, the more child-centred the GP (4-6 years $X=2.2$, 79 years $X=2.5,10-12$ years $X=2.9 ; F=2.95, p<0.06$ ).

The length of the interview was not affected by the age of the child (4-6 years 6"38"; 7-9 years $7^{\prime} 04^{\prime \prime} ; 10-12$ years 6’56"; n.s.).

\section{The Effect of Time}

The length of the interview increased over the years ( $5^{\prime} 33^{\prime \prime} v s 7^{\prime} 22^{\prime \prime}$ vs $\left.7^{\prime} 44^{\prime \prime}, F=5.69, p<0.01\right)$. The participants' overall rate of affective versus instrumental behaviour did not change fundamentally over the years. Only in the second period did parents express less affective behaviour towards the GP (1st period 16\%, 2nd period 11\%, 3rd period 16\%; $F=10.59, p<0.001$ ). As far as the distinguished clusters are concerned, parents displayed less social behaviour and partnership-building towards GPs over the years, especially in the second period (1st period 16\%, 2nd period $11 \%$, 3rd period 3:16\%; $F=11.62$, $p<0.001$ ). Conversely, GPs directed less involvement to the parent (period 1: $0.7 \%$, period 2: $0.1 \%$, period 3: $0.2 \% ; F=3.25, p<0.05$ ).

A focus on the group of children aged 10-12 revealed a higher exchange of medical information between GP and older children during the second period. These older children directed more medical information towards the GP (1st period 3\%, 2nd period 6\%, 3rd period 5\%; $F=4.98, p<0.05$ ). At the same time the GP intensified the exchange of medical information with the child (1st period 3\%, 2nd period $6 \%$, 3rd period $5 \% ; F=5.23, p<0.05$ ) and directed more consultation-structuring utterances to 
the child (1st period 4\%, 2nd period 7\%, 3rd period 3\%; $F=3.31, p<0.05$ ). All the other categories or age groups showed no changes over time.

The GP demonstrated more warm feeling towards both child (1st period $X=3.5$, 2nd period $X=4.5$, 3rd period $X=4.0 ; F=6.09, p<0.01$ ) in the second period, and parent (1st period $X=3.5$, 2nd period $X=4.3$, 3rd period $X=4.4 ; F=10.22, p<0.001)$ in the second and third periods. Also the parent showed more warmth to the GP over time (1st period $X=3.1$, 2nd period $X=3.6$, 3rd period $X=3.9 ; F=7.27$, $p<0.001)$. Regarding the other feelings, no changes occurred over the three periods.

On all measures (see Table IV), the GP became significantly more child-centred and parent-centred in the second period, compared with the first period (level of significance varying from $p<0.05$ to $0.001)$.

Overall, there seemed to be a number of changes in the second period, but they were mostly not consolidated later on. In sum, the effect of time on the nature of the medical communication was fairly small.

\section{DISCUSSION}

Detailed analysis of the doctor-parent-child communication of 106 medical interviews confirms that child participation in medical encounters is rather limited. The interaction in the doctor-parent-child triad is dominated by both adult participants, which is in line with previous findings (Meeuwesen and Kaptein, 1996; Tates and Meeuwesen, 2000). Contrary to the hypothesis, all three participants involved display mainly instrumental behaviour. Physician-child interaction appears not to be primarily restricted to the affective domain. Both GP and child display mainly instrumental behaviour towards each other, and the greater part of GPs' affective behaviour appears to be directed to the parent. This contrasts with previous findings that stated that most of physicians' affective behaviour appears to be child-directed, and that children's contribution to medical communication appears to be especially affective in nature (Freemon et al., 1971; Pantell et al., 1982; Aronsson and Rundstro“ m, 1989; Van Dulmen, 1998; Wissow et al., 1998).

The specific communication profiles of the participants in the three major segments of the interview varied according to their function. During medical history-taking, there is a great deal of social behaviour and partnership-building between the GP and the parent, and, in interaction with the child, the GP tells jokes and laughs in order to relieve tension. As for discovering the reason for the child's attendance, there is a fair amount of exchange of medical information between physician, parent and child. By directly addressing the child, the GP is apparently considering the child patient capable of providing medical information. In the physical examination segment, the exchange of medical information between GP and child, as well as between child and GP, is intensified. The GP also directs a fair amount of consultation-structuring utterances in terms of directions and instructions to the child ('Well, show me your nasty ear'). Conversely, in the conclusion segment, theGP resumes his orientation towards the parent by exchanging more medical information and by displaying social behaviour and partnership-building. By directing more than $80 \%$ of the counselling and advice to the parent, the GP obviously does not consider the child capable of discussing decisions on treatment. The results of these segment-related profiles are validated by the demonstrated increase in parentcentredness of the GP, and are consistent with earlier findings (Pantell and Lewis, 1993; Van Dulmen, 1998; Wissow et al., 1998), which state that the dominant communication pattern in paediatric visits is one that includes children in information gathering, but excludes them from management and diagnostic information.

In line with the second hypothesis, the older the child, the more instrumental the behaviour of both GP and child. Parental behaviour and the affective behaviour of GP and child appeared to be unaffected. The GP involves the older child more directly in the medical encounter by an increased exchange of medical information towards the child alone or towards child and parent together, and by a decrease of parent-directed counselling. The older child itself enlarges her contribution to the consultation by intensifying the exchange of medical information with both the GP and the parent. The increase of GPs' overall child-centredness in the case of older children validates these RIAS results. Our findings of intensified communication between GP and child as children grow older are supported by earlier studies (Pantell et al., 1982; Meeuwesen and Kaptein, 1996; Van Dulmen, 1998; Tates and Meeuwesen, 2000), and show that children can play a far more active role in taking initiatives when 
negotiating the aim and process of the interaction than has previously been assumed (Elbers et al., 1992; Hoogsteder, 1995). This is an important finding from the perspective of child-centred care and increased demands for shared decision-making and informed consent.

The hypothesis that, because of the growing emphasis on the child's own responsibility, the GPs would have become more child-centred as an effect of time, was confirmed when comparing the first and second period. As far as changes in specific communication behaviour took place, they were restricted to the group of older children, where more exchange of medical information was initiated by both GP and child during the second period (the eighties). In addition, the GP directs more consultation structuring utterances to the child. These changes do not continue in the third period (the nineties).

Considering the results, we are led to the conclusion that the stereotype of doctor- child interaction as a joking relationship implies an underestimation of the differentiated nature of doctor-parent-child interaction. Evidently, the child's age appears to have a substantial effect on child participation. In the case of 10-12 year old children in particular, the interaction between GP and child has the potential to develop from a joking relationship towards a situation in which shared decision-making might no longer be a misnomer. These age-related results stress the importance of taking into account the child's cognitive development and not to generalize the findings from studies with different samples regarding the child's age.

We would like to put the stereotype of doctor-child interaction as a joking relationship in a different perspective. Both affective and instrumental behaviour are exchanged between doctor and child (and parents, of course). Affective behaviour influences the quality of doctor-patient relationships and facilitates the mutual process of information exchange. In view of the considerable amount of GPs' child-directed instrumental behaviour, especially in older children, it is concluded that doctor-child communication implies more than the maintenance of a joking relationship. GPs' communication style in interaction with the child may best be described as both caring (creating a good relationship by affective behaviour) and curing (helping the child to solve his health problem by instrumental behaviour) (Bensing, 1991). GPs are obviously striving for the goal of talking with children instead of talking at children. Treating the child as an active participant in medical communication is consistent with the increasing demands for shared decision-making and informed consent (Stewart et al., 1995; Blaauwbroek, 1997; Van den Borne, 1998). This preference of increased child participation is also in line with the development of children as fellow citizens (De Winter, 1996). GPs in our sample aspire to create a good interpersonal relationship and, in the case of older children, to exchange medical information. The aim of shared decision-making, however, is not attained. Sharing information and sharing decisions are not synonymous; they are separate goals within the consultation, with information sharing being prerequisite to shared decision-making (Ong et al., 1995; Charles et al., 1997). The age-dependent instrumental behaviour during the treatment phase of both GPs and children themselves emphasizes the potential for reaching the goal of shared decision-making. The older the child, the more the exchange of medical information is intensified by both GP and child, and the more the GP involves the child in the process of decision-making by directing counselling and advice to parent and child together instead of only to the parent.

A remarkable finding is that while the GP accommodates his/her behaviour to the child's age, the parental behaviour appears to be almost constant (see also Tates and Meeuwesen, 2000). The GPs' accommodative behaviour is in line with Street (1992) and Wissow et al. (1994), who stress that pediatricians do vary their communication style in response to patient characteristics. Why do parents seem to be insensitive to the changing needs and capabilities of older children? Parental concern may be a possible explanation for this non-accommodation. Lack of familiarity with the importance of active child participation in the medical interview might be another reason. Parents may regard themselves as the appropriate spokesman in medical communication, because they consider issues of children's health and illness as their parental responsibility. Possible different role expectations of GPs and parents and the consequences for active child participation in medical communication will be elaborated elsewhere (Tates et al., 2002).

This study gives rise to several methodological comments. Obviously, the strength of this study is that insight into the child's participation in the medical interview and the results of differences in adult accommodation have only become manifest by adapting the RIAS observation system to triadic analysis. Conventional dyadic RIAS analyses are bound to fail in fully exposing the interactional 
Tates, K., Meeuwesen, L., Bensing, J., Elbers, E.

Joking or decision-making?: affective and instrumental behaviour in doctor-parent-child communication.

Psychology and Health: 17, 2002, nr. 3, p. p. 281-295

dynamics of triadic interactions. Restricting the analysis to the dyadic interactions between doctorparent and doctor-child, ignores the consequences of a third participant's presence. This study reveals the possibilities of extending the RIAS, as the system most frequently used to analyse doctor-patient communication, to triadic applications.

As far as the reliability of the RIAS is concerned, we already mentioned that it was satisfactory to good. Referring to the validity, it can be said that the RIAS measures just one level of communication, the affective and instrumental behaviour, which is restricted to frequential analyses. It is advisable to present case studies in order to further unravel the specific interactional patterns of the complex triadic communication. The RIAS could then be applied in combination with qualitative methods and/ or sequential analysis (Roter, 2000). Results regarding turn-taking patterns and role identities are elaborated elsewhere (Tates and Meeuwesen, 2000; Tates et al., 2002). Referring to the validity of the measures of GPs' patient-centredness, Mead and Bower (2000) point to the complications and low validities, because patient-centredness can be operationalized in different ways. A degree of caution is called for in interpreting the results on these measures. But the fact that the results affirmed the RIAS findings can be taken as an indication of a quite acceptable validity level.

This study focused on a description of the details of verbal behaviour. The question of whether differences in verbal behaviour have an impact on the outcome of the consultations will have to be answered elsewhere. Stiles (1989) rightly warns about the pitfalls of process-outcome correlations. On the basis of this study, one can only conclude that RIAS offers a useful framework for describing the process of doctor-parent-child communication.

The disappointing result of the effects of time on the communication patterns may be due to the small number of consultations for each period and their unequal division. At the start of this project, other data were not available. Another explanation is that the declining attention to good communication in the educational programmes for medical students in the eighties made its negative effect felt in the nineties. Whatever the case, we recommend that future research seeks to replicate with a greater sample, and more equally divided periods.

The present findings have several implications for medical practice. From the perspective of effective communication in the doctor-parent-child triad and in terms of education and counselling of both child and parent, GPs should provide information about the benefits of active child participation in medical communication. With information- sharing being a prerequisite to decision-making, GPs should strive to elicit children's perceptions of their illness and expectations associated with the disease in order to achieve an effective information exchange. As a more direct communication between doctor and child improves care in terms of satisfaction, compliance, and better health experience (Pantell et al., 1982; Colland, 1990; Holtzheimer et al., 1998; Hosli, 1998), physicians should aim at enhancing child participation in the diagnostic and treatment phase. In addition, merely by addressing (older) children directly and encouraging child participation, physicians may provide both children and parents with an important message about the desirable mode of interaction in medical encounters, and emphasize the child's identity as an autonomous participant. A first step in reaching the goal of shared decision-making with children is to establish a conducive atmosphere in which both child and parent feel that their views are valued and needed. Paying attention to these issues will, hopefully, contribute to more effective communication between GP, parent and child.

\section{REFERENCES}

Alderson, P. and Montgomery, J. (1996). Health Care Choices: Making Decisions with Children. Institute for Policy Research, London.

Aronsson, K. and Rundstro" m, B. (1989). Cats, dogs, and sweets in the clinical negotiation of reality: on politeness and coherence in pediatric discourse. Language in Society, 18, 483-504.

Bensing, J. (1991). Doctor-Patient Communication and the Quality of Care: An Observation Study into Affective and Instrumental Behavior in General Practice [Dissertation]. NIVEL, Utrecht.

Bensing, J.M. and Dronkers, J. (1992). Instrumental and affective aspects of physician behavior. Medical Care, 30, 283-298.

Bensing, J., Schreurs, K. and Rijk, A. de (1996). The role of the general practitioner's affective behaviour in medical encounters. Psychology and Health, 11, 825-838.

Blaauwbroek, H.G. (1997). Patient organizations and patients' rights. In: Schrijvers, A.J.P. (Ed.), Health and Health Care in the Netherlands: A Critical Self-Assessment of Dutch Experts in Medical and Health Sciences, pp. 223-238. De Tijdstroom, Utrecht. 
Tates, K., Meeuwesen, L., Bensing, J., Elbers, E.

Joking or decision-making?: affective and instrumental behaviour in doctor-parent-child communication.

Psychology and Health: 17, 2002, nr. 3, p. p. 281-295

Byrne, P.S. and Long, B.E.L. (1976). Doctors Talking to Patients: A Study of the Verbal Behaviour of General Practitioners Consulting in their Surgeries. HMSO/RCGP, London.

Charles, C., Gafni, A. and Whelan, T. (1997). Shared decision-making in the medical encounter: what does it mean? (or it takes at least two to tango). Social Science \& Medicine, 44, 681-692.

Colland, V.T. (1990). Coping with Asthma: Intervention Methods for Children and Parents

[Dissertation]. Thesis Publishers, Amsterdam.

De Melker, R.A. (1997). The family doctor. In: Schrijvers, A.J.P. (Ed.), Health and Health Care in the Netherlands: A Critical Self-Assessment of Dutch Experts in Medical and Health Sciences, pp. 6072. De Tijdstroom, Utrecht.

De Swaan, A. (1988). In Care of the State: Health Care, Education, and Welfare in Europe and the USA in the Modern Area. Polity Press, Cambridge.

De Winter, M. (1996). Children: Fellow Citizens. Radcliff Medical Press, Abingdon-Oxon.

DuBois-Reymond, M. (1993). Pluraliseringstendenzen en onderhandelingsstructuren in gezin (Pluralization tendencies and negotiating structures in the family). Amsterdams Sociologisch Tijdschrift, 19, 113-144.

Elbers, E., Maier, R., Hoekstra, T. and Hoogsteder, M. (1992). Internalization and adult-child interaction. Learning and Instruction, 2, 101-118.

Engel, G.L. (1988). How much longer must medicine's science be bound by a seventeenth century world view? In: White, K. (Ed.), The Task of Medicine: Dialogue at Wickenburg, pp. 113-136. The Henry Kaiser Foundation, Menlo Park, California.

Freemon, B., Negrete, V.F., Davis M. and Korsch, B.M. (1971). Gaps in doctor-patient communication: Doctor-patient interaction analysis. Pediatric Research, 5, 298-311.

Hart, C. and Chesson, R. (1998). Children as consumers. British Medical Journal, 316, 1600-1603.

Hertzog, C. (1995). Research design in studies of aging and cognition. In: Birren, J.E. and Schaie, K.W. (Eds.), Handbook of the Psychology of Aging, pp. 24-37. Academic Press, San Diego.

Holtzheimer, L., Mohay, H. and Masters, I.B. (1998). Educating young children about asthma: comparing the effectiveness of a developmentally appropriate asthma education video tape and picture book. Child: Care, Health and Development, 24, 85-99.

Hoogsteder, M. (1995). Learning through Participation: The Communication between Young Children and their Caregivers in Informal Learning and Tutoring Situations [Dissertation]. ISOR, Utrecht.

Hosli, E.J. (1998). Ziektebegrip bij kinderen: De ontwikkeling van het denken over ziekte ( Children's thinking about illness) [Dissertation]. Thesis Publishers, Amsterdam.

Mead, N. and Bower, P. (2000). Measuring patient-centredness: A comparison of three observation based instruments. Patient Education and Counseling, 39, 71-80.

Meeuwesen, L. and Kaptein, M. (1996). Changing interactions in doctor-parent-child communication. Psychology and Health, 11, 787-795.

Meeuwesen, L., Bensing, J. and Kaptein, M. (1998). Doctor-parent-child communication over the years: an interactional analysis. In: Bensing, J., Sa" tterlund-Larsson, U. and Szecsenyi, J. (Eds.), Doctor-Patient Communication and the Quality of Care in General Practice, pp. 5-18. NIVEL, Utrecht.

Ong, L.M.L., Haes, J.C.J.M. de, Hoos, A.M. and Lammes, F.B. (1995). Doctor-patient communication: a review of the literature. Social Science \& Medicine, 40, 903-918.

Pantell, R.H. and Lewis, C.C. (1993). Talking with children: how to improve the process and outcome of medical care. Medical Encounter, 10, 3-7.

Pantell, R.H., Stewart, T.J., Dias, J.K., Wells, P. and Ross, A.W. (1982). Physician communication with children and parents. Pediatrics, 70, 396-402.

Roter, D.L. (1989). The Roter method of interaction process analysis (Manual). Johns Hopkins University, Baltimore.

Roter, D.L. (2000). The enduring and evolving nature of the patient-physician relationship. Patient Education and Counseling, 39, 5-15.

Roter, D.L. and Hall, J.A. (1992). Doctors Talking with Patients, Patients Talking with Doctors. Auburn House, Westport CT.

Rylance, G. (1996). Making decisions with children. British Medical Journal, 312, 794.

Stiles, W.B. (1989). Evaluating medical interview components: Null correlations with outcomes may be misleading. Medical Care, 27, 212-220.

Stewart, M., Brown, J.B., Weston, W.W., McWhinney, I.R., McWilliam, C.L. and Freeman, T.R. (1995). Patient-Centered Medicine: Transforming the Clinical Method. Sage Publications, London.

Street, R.L. (1992). Communicative styles and adaptations in physician-parent consultations. Social Science \& Medicine, 34, 1155-1163. 
Tates, K., Meeuwesen, L., Bensing, J., Elbers, E.

Joking or decision-making?: affective and instrumental behaviour in doctor-parent-child communication.

Psychology and Health: 17, 2002, nr. 3, p. p. 281-295

Tates, K. and Meeuwesen, L. (2000). 'Let mum have her say': Turn-taking in doctor-parent-child communication. Patient Education and Counseling, 40, 151-162.

Tates, K. and Meeuwesen, L. (2001). Doctor-parent-child communication: A (re)view of the literature. Social Science \& Medicine, 52, 839-851.

Tates, K., Meeuwesen, L., Elbers, E. and Bensing, J. (2002). 'I've come for his throat': roles and identities in doctor-parent-child communication. Child: Care, Health and Development, 28, 109-116.

Van den Borne, H.W. (1998). The patient from receiver of information to informed decision-maker. Patient Education and Counseling, 34, 89-102.

Van Dulmen, A.M. (1998). Children's contribution to pediatric outpatient consultations. Pediatrics, 102, 563-568.

Van der Pasch, M. and Verhaak, P. (1998). Communication in general practice: recognition and treatment of mental illness. Patient Education and Counseling, 33, 97-112.

Van Suijlekom-Smit, L.W.A. and Crone-Kraaijeveld, E. (1994). Het zieke kind, een zorg voor huisarts en kinderarts ( IIIness in childhood, general practitioner's and pediatrician's concern) [Dissertation]. Erasmus University, Rotterdam.

Verhaak, P.F.M., Bensing, J.M. and Dulmen, A.M. van (1998). Communication in health care. Patient Education and Counseling, 34, S1-S4.

Wissow, L.S., Roter, D.L. and Wilson, M.E.H. (1994). Pediatrician interview style and mothers' disclosure of psychosocial issues. Pediatrics, 93, 289-295.

Wissow, L.S., Roter, D.L., Bauman, L.J., Crain, E., Kercsmar, C., Weiss, K., Mitchell, H. and Mohr, B. (1998). Patient-provider communication during the emergency department care of children with asthma. Medical Care, 10, 1439-1450.

Worobey, J., O'Hair, H.D. and O'Hair, M.J.C. (1987). Pediatrician-patient-parent communication: a descriptive analysis. Language and Communication, 7, 293-301.

\section{TABLES}

TABLE I Sample profile $(n=106)$

\begin{tabular}{|c|c|c|c|c|c|c|c|c|}
\hline & \multicolumn{2}{|c|}{$\begin{array}{c}\text { Period 1 } \\
1975-1978 \\
n=36\end{array}$} & \multicolumn{2}{|c|}{$\begin{array}{c}\text { Period } 2 \\
1988-1989 \\
n=36\end{array}$} & \multicolumn{2}{|c|}{$\begin{array}{c}\text { Period } 3 \\
1993 \\
n=34\end{array}$} & \multicolumn{2}{|c|}{$\begin{array}{c}\text { Total } \\
n=106\end{array}$} \\
\hline & $N$ & $\%$ & $N$ & $\%$ & $N$ & $\%$ & $N$ & $\%$ \\
\hline \multicolumn{9}{|l|}{ Age } \\
\hline $4-6$ & 10 & (28) & 14 & (39) & 13 & (38) & 37 & $(35)$ \\
\hline $7-9$ & 11 & (30) & 11 & $(30)$ & 11 & (32) & 33 & (31) \\
\hline $10-12$ & 15 & (42) & 11 & (31) & 10 & $(30)$ & 36 & (34) \\
\hline \multicolumn{9}{|l|}{ Sex } \\
\hline Male & 19 & (53) & 18 & $(50)$ & 14 & (41) & 51 & $(48)$ \\
\hline Female & 17 & (47) & 18 & $(50)$ & 20 & (59) & 55 & $(52)$ \\
\hline \multicolumn{9}{|l|}{ Complaint } \\
\hline Somatic & 25 & $(70)$ & 22 & (61) & 17 & $(50)$ & 64 & $(60)$ \\
\hline Psychosomatic & 11 & (30) & 14 & (39) & 17 & $(50)$ & 42 & $(40)$ \\
\hline
\end{tabular}


Tates, K., Meeuwesen, L., Bensing, J., Elbers, E.

Joking or decision-making?: affective and instrumental behaviour in doctor-parent-child communication.

Psychology and Health: 17, 2002, nr. 3, p. p. 281-295

TABLE II Affective and instrumental behaviour of GP, parent and child in percentages (17.924 utterances in 106 visits)

$\begin{array}{ccccccccccccc}G P & G P & G P & G P & P & P & P & P & C & C & C & C & \\ \downarrow & \downarrow & \downarrow & \text { Total } & \downarrow & \downarrow & \downarrow & \text { total } & \downarrow & \downarrow & \downarrow & \text { total } & \text { Total } \\ P & C & B & & G P & C & B & & G P & P & B & & \end{array}$

\begin{tabular}{|c|c|c|c|c|c|c|c|c|c|c|c|c|c|}
\hline $\begin{array}{l}\text { Affective behaviour } \\
\text { Social behaviour and } \\
\text { partnership-building }\end{array}$ & 12.3 & 5.7 & 1.0 & 19.0 & $14.2^{\mathrm{b}}$ & 1.8 & 0.3 & $16.4^{\mathrm{b}}$ & 2.5 & 0.9 & 0.5 & 3.9 & 39.2 \\
\hline Involvement & $0.4^{\mathrm{b}}$ & 0.3 & 0.1 & 0.8 & 0.3 & 0.4 & 0.0 & 0.6 & 0.1 & 0.2 & 0.0 & 0.3 & 1.7 \\
\hline Affective total & 12.7 & 6.0 & 1.1 & 19.8 & 14.5 & 2.2 & 0.3 & 17.0 & 2.6 & 1.1 & 0.5 & 4.2 & 41.0 \\
\hline $\begin{array}{c}\text { Instrumental behaviour } \\
\text { Counselling/advice }\end{array}$ & $6.7^{\mathrm{a}}$ & 0.1 & $0.6^{\mathrm{a}}$ & 8.3 & 2.9 & 0.7 & 0.3 & 3.9 & 0.6 & 0.6 & 0.4 & 1.5 & 13.8 \\
\hline $\begin{array}{l}\text { Medical information } \\
\text { exchange }\end{array}$ & 10.4 & $2.6^{\mathrm{a}}$ & $0.6^{\mathrm{a}}$ & 13.7 & 12.3 & 0.5 & 0.1 & 12.9 & $2.7^{\mathrm{a}}$ & $0.3^{\mathrm{a}}$ & 0.2 & $3.2^{\mathrm{a}}$ & 29.8 \\
\hline $\begin{array}{l}\text { Psychosocial information } \\
\text { exchange }\end{array}$ & 0.7 & 0.2 & 0.0 & $0.9^{\mathrm{a}}$ & 1.8 & 0.1 & 0.0 & 1.9 & 0.3 & 0.1 & 0.0 & 0.4 & 3.1 \\
\hline $\begin{array}{l}\text { Consult structuring and } \\
\text { clarification }\end{array}$ & 3.4 & 4.7 & 1.2 & 9.3 & 1.0 & 1.6 & 0.1 & 2.7 & 0.2 & 0.1 & 0.0 & 0.3 & 12.4 \\
\hline Instrumental total & 21.2 & 8.4 & 2.5 & 32.4 & 18.0 & 2.9 & 0.5 & 21.4 & 3.8 & 1.1 & 0.6 & 5.4 & 59.0 \\
\hline Total GP, parent and child & & & & 52.0 & & & & 38.4 & & & & 9.6 & \\
\hline
\end{tabular}

GP: general practitioner; P: parent; C: child; B: both other participants.

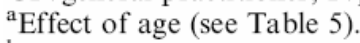

${ }^{\mathrm{b}}$ Effect of time.

TABLE III Global affect ratings (scale 1-6)

\begin{tabular}{lll}
\hline & Mean & $($ Std $)$ \\
\hline Warmth & & \\
GP $\rightarrow$ child $^{\text {b }}$ & 4.0 & $(1.2)$ \\
GP $\rightarrow$ parent & & $(1.0)$ \\
Parent $\rightarrow$ GP $^{\mathrm{a}}$ & 4.1 & $(0.9)$ \\
Parent $\rightarrow$ child & 3.5 & $(1.1)$ \\
Child $\rightarrow$ GP & 3.6 & $(1.1)$ \\
Child $\rightarrow$ parent & 3.0 & $(1.1)$ \\
Nervousness & 3.1 & \\
GP $\rightarrow$ child & & $(0.3)$ \\
GP $\rightarrow$ parent & 1.0 & $(0.2)$ \\
Parent $\rightarrow$ GP & 1.0 & $(0.9)$ \\
Parent $\rightarrow$ child & 1.5 & $(0.6)$ \\
Child $\rightarrow$ GP & 1.2 & $(0.8)$ \\
Child $\rightarrow$ parent & 1.3 & $(0.6)$ \\
Irritation & 1.1 & \\
GP $\rightarrow$ child & & $(0.2)$ \\
GP $\rightarrow$ parent & 1.0 & $(0.4)$ \\
Parent $\rightarrow$ GP & 1.1 & $(0.3)$ \\
Parent $\rightarrow$ child & 1.1 & $(0.5)$ \\
Child $\rightarrow$ GP & 1.2 & $(0.5)$ \\
Child $\rightarrow$ parent & 1.1 & $(0.5)$ \\
\hline
\end{tabular}

${ }^{\mathrm{a}} \mathrm{Effect}$ of age.

${ }^{b}$ Effect of time. 
Tates, K., Meeuwesen, L., Bensing, J., Elbers, E.

Joking or decision-making?: affective and instrumental behaviour in doctor-parent-child communication.

Psychology and Health: 17, 2002, nr. 3, p. p. 281-295

TABLE IV GP's child-centredness and parent-centredness (scale 1-5)

\begin{tabular}{|c|c|c|}
\hline & Mean & $(S t d)$ \\
\hline \multicolumn{3}{|l|}{ Child-centredness } \\
\hline $\begin{array}{l}\text { During segment of medical } \\
\text { history-taking a,b }\end{array}$ & 2.5 & $(1.3)$ \\
\hline $\begin{array}{l}\text { During segment of diagnosis and } \\
\text { treatment information }\end{array}$ & 2.0 & $(1.2)$ \\
\hline Adequate response $^{\mathrm{b}}$ & 2.9 & $(1.3)$ \\
\hline \multicolumn{3}{|l|}{ Parent-centredness } \\
\hline $\begin{array}{l}\text { During segment of medical } \\
\text { history-taking }{ }^{\mathrm{b}}\end{array}$ & 3.4 & $(0.8)$ \\
\hline $\begin{array}{l}\text { During segment of diagnosis and } \\
\text { treatment information }{ }^{\mathrm{b}}\end{array}$ & 3.8 & $(0.8)$ \\
\hline Adequate response $\mathrm{b}^{\mathrm{b}}$ & 3.7 & $(4.0)$ \\
\hline
\end{tabular}

${ }^{\mathrm{a}} \mathrm{Effect}$ of age.

${ }^{\mathrm{b}}$ Effect of time.

TABLE V Instrumental behaviour and age of the child

\begin{tabular}{|c|c|c|c|c|c|}
\hline & $\begin{array}{c}\text { Age 4-6 } \\
\text { mean }\end{array}$ & $\begin{array}{c}\text { Age } 7-9 \\
\text { mean }\end{array}$ & $\begin{array}{c}\text { Age } 10-12 \\
\text { mean }\end{array}$ & & \\
\hline \multicolumn{6}{|c|}{ Counselling and advice } \\
\hline $\mathrm{GP} \rightarrow$ parent & 8.6 & 6.3 & 5.2 & $F=5.96$ & $p<0.01^{\mathrm{a}}$ \\
\hline $\mathrm{GP} \rightarrow$ both others & 0.3 & 0.3 & 1.3 & $F=8.09$ & $p<0.001^{\mathrm{b}}$ \\
\hline \multicolumn{6}{|c|}{ Medical information exchange } \\
\hline $\mathrm{GP} \rightarrow$ child & 1.5 & 2.1 & 4.3 & $F=10.89$ & $p<0.001^{\mathrm{c}}$ \\
\hline $\mathrm{GP} \rightarrow$ both others & 0.1 & 0.6 & 1.1 & $F=7.41$ & $p<0.001^{\mathrm{d}}$ \\
\hline Child $\rightarrow$ GP & 1.1 & 2.5 & 4.7 & $F=13.58$ & $p<0.001^{\mathrm{e}}$ \\
\hline Child $\rightarrow$ parent & 0.1 & 0.4 & 0.5 & $F=3.83$ & $p<0.05^{\mathrm{f}}$ \\
\hline Total child & 1.3 & 2.9 & 5.4 & $F=14.83$ & $p<0.001^{\mathrm{g}}$ \\
\hline \multicolumn{6}{|c|}{ Psychosocial information exchange } \\
\hline Total GP & 1.4 & 0.7 & 0.5 & $F=3.67$ & $p<0.05^{\mathrm{h}}$ \\
\hline
\end{tabular}

${ }^{a}$ significant at 0.05 level: age 4-6/age 10-12.

bsignificant at 0.05 level: age 4-6/age 10-12 and age 7-9/age 10-12.

significant at 0.05 level: age $4-6 /$ age $10-12$ and age $7-9 /$ age $10-12$.

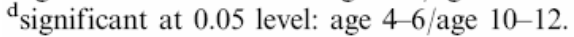

esignificant at 0.05 level: age 4-6/age $10-12$ and age 7-9/age 10-12.

${ }^{\mathrm{f}}$ significant at 0.05 level: age 4-6/age 10-12.

${ }^{g_{\text {significant }}}$ at 0.05 level: age $4-6 /$ age $10-12$ and age $7-9 /$ age $10-12$.

${ }^{\mathrm{h}}$ significant at 0.05 level: age 4-6/age 10-12. 